\title{
Hardware-in-the-loop (HIL) Test of Demand as Frequency Controlled Reserve (DFR)
}

\author{
Wu, Qiuwei; Zimmermann, K.; Østergaard, Jacob; Nielsen, Arne Hejde
}

Published in:

Proceedings of 10th International Conference on Advances in Power System Control, Operation and Management,

Publication date:

2016

Document Version

Peer reviewed version

Link back to DTU Orbit

Citation (APA):

Wu, Q., Zimmermann, K., Østergaard, J., \& Nielsen, A. H. (2016). Hardware-in-the-loop (HIL) Test of Demand as Frequency Controlled Reserve (DFR). In Proceedings of 10th International Conference on Advances in Power System Control, Operation and Management, Institution of Engineering and Technology.

\section{General rights}

Copyright and moral rights for the publications made accessible in the public portal are retained by the authors and/or other copyright owners and it is a condition of accessing publications that users recognise and abide by the legal requirements associated with these rights.

- Users may download and print one copy of any publication from the public portal for the purpose of private study or research.

- You may not further distribute the material or use it for any profit-making activity or commercial gain

- You may freely distribute the URL identifying the publication in the public portal 


\title{
Hardware-in-the-loop (HIL) Test of Demand as Frequency Controlled Reserve (DFR)
}

\author{
Q. Wu, J. K. Zimmermann, J. Østergaard, A. H. Nielsen \\ Department of Electrical Engineering \\ Technical University of Denmark, Denmark \\ Email: qw@elektro.dtu.dk,
}

\begin{abstract}
This paper presents the hardware-in-the-loop (HIL) test of the demand as frequency controlled reserve (DFR). The HIL test refers to a test in which parts of a pure simulation have been replaced by actual physical components. It is used to understand the behavior of a new device or controller. The DFR has been tested by offline simulations to illustrate the efficacy of this technology. The DFR control logics have been implemented in the SmartBox. The HIL was conducted by having the SmartBox connected to the real time simulations and the performance of the SmartBox was tested with difference frequency events in the simulated power systems. The HIL test results show that the implemented DFR in the SmartBox can efficiently arrest the system frequency.
\end{abstract}

Index Terms-- Demand as frequency controlled reserve, hardware-in-the-loop, real time digital simulator

\section{INTRODUCTION}

Maintaining the system frequency is essential for the operation of electric power systems. With the ambitious goal of realizing $50 \%$ wind power penetration by 2020 and $100 \%$ renewable based energy system by 2050 [1], the frequency control will be a big challenge to the system operator. In theory, the generation and demand can equally contribute to the frequency control as reserves. Many electric demands can be turned on and off rapidly and frequently to provide fast reserves needed by the renewable based electric power systems. Household appliances such as electric heating, refrigerators, freezers, and water heaters are good candidates for their considerable volume and the capability of instantaneous switching-off.

Demand used as reserves has been extensively studied. A market-based demand management program using low frequency relay to control industrial loads is reported in [2]. A similar program was implemented in the New Zealand power system [3]. A pilot project was conducted by the Long Island Power Authority in 2003 which used the ComfortChoice technology for controlling air conditioners to provide reserve [4]. It is suggested that individual household appliances suitable for temporary disconnection can provide fast reserve within seconds, e.g., refrigerators and air conditioners [5], [6]. The use of electricity demands as fast reserves were studied in [7], [8] and tested by offline simulations. The case study results show that the electricity demands can provide reliable performance for frequency control with low implementation cost.

This paper presents the hardware-in-the-loop (HIL) test of the demand as frequency controlled reserve (DFR). The DFR technology was tested in a real time simulation environment in order to test the DFR technology in an environment close to reality. The DFR control logics were implemented in the SmartBox which sensors the system frequency and sends the on/off control signal to the demand connected. The interface between the real time digital simulator (RTDS) and the SmartBox was established to test the closed loop performance of the DFR technology.

The paper is arranged as follows. The DFR technology and control logics are presented in Section 2. The heat pump model implemented in RTDS is presented in Section 3. The real time HIL test platform is described in Section 4. Section 5 describes the case study results and discussion, followed by the conclusions.

\section{DFR CONTROL LOGICS}

The DFR technology is to flexibly turn on or off electricity demands in response to the system frequency deviations to provide frequency controlled normal or disturbance reserves. It can be implemented as an external control box or embedded in the electric appliances. Two DFR control logics were developed in [7] and [8]. The two control logics are briefly explained for the integrity of the paper.

\subsection{Control logic type I}


The DFR control logic type I disconnects and reconnects electric appliances to the grid when the system frequency falls below $f_{\text {off }}$ and recovers above $f_{\text {on }}$, respectively [7], [8]. The DFR control logic type I is illustrated in Figure 1 . The reconnection frequency set point $f_{\text {on }}$ should be equal to or higher than the disconnection set point $f_{\text {off }}$ to give a hysteresis that can prevent oscillatory behaviors and consequently excessive wear outs to the appliances.

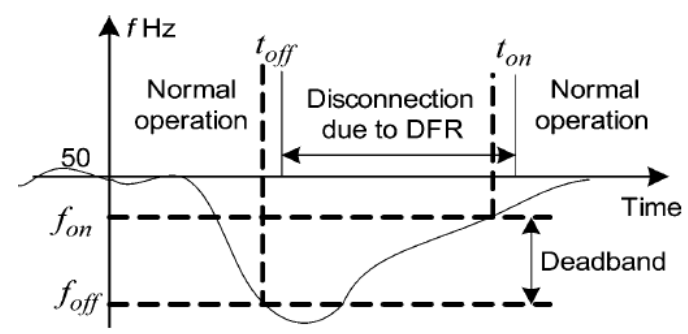

Figure 1 Illustration of Control Logic Type I [7], [8]

\subsection{Control logic type II}

The DFR control logic type II is customized for switching the thermostatically controlled loads by adjusting the nominal temperature set points $T_{\text {high }}^{\text {normal }}$ and $T_{\text {low }}^{\text {normal }}$. An offset coefficient $k f$ is used to calculate the temperature set points with frequency deviation [8],

$$
\begin{gathered}
T_{\text {high }}=T_{\text {high }}^{\text {normal }}+k f\left(f-f_{0}\right) \\
T_{\text {low }}=T_{\text {low }}^{\text {normal }}+k f\left(f-f_{0}\right)
\end{gathered}
$$

where $T_{\text {high }}$ is the high temperature set point, $T_{\text {low }}$ is the low temperature set point, $k f$ is the coefficient of frequency change in ${ }^{\circ} \mathrm{C} / \mathrm{Hz}, f_{0}$ is the nominal system frequency, $f$ is the measured frequency.

If the system frequency changes by $\Delta f$ and $k \Delta f \leq\left(T_{\text {high }}^{\text {normal }}-T_{\text {low }}^{\text {normal }}\right)$, the power change due to the DFR Type II control can be estimated by,

$$
\begin{aligned}
& P_{\text {decrease }}=\frac{k f \Delta f}{T_{\text {high }}^{\text {normal }}-T_{\text {low }}^{\text {normal }}} \times P \times \lambda \\
& P_{\text {increase }}=\frac{k f \Delta f}{T_{\text {high }}^{\text {normal }}-T_{\text {low }}^{\text {normal }}} \times P \times(1-\lambda)
\end{aligned}
$$

where $P$ is the total installed power of household appliances under the DFR Type II control, $\lambda$ is the percentage of the on household appliances under the DFR
Type II control. Figure 2 illustrates that several heat pumps initially 'on' are turned off with a low frequency event by changing the temperature set points.

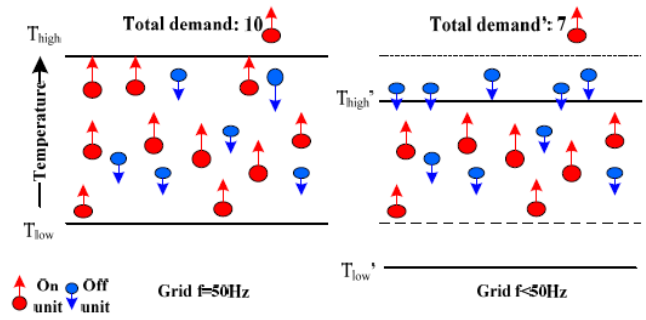

Figure 2 Illustration of DFR Type II Control

\section{Heat Pump Modeling in RSCAD}

The household appliance selected to be controlled by the DFR is heat pump. The heat pump is popular in Denmark and has good controllability and capacity for demand response.

\subsection{Mathematical model of a building with a heat pump}

The dynamics of a direct air heating system can be sufficiently described by three thermal masses. The ambient air of the building interior has smaller storage volume, and defines a faster dynamics of the system; while the larger storage volume of the building envelope, or structure, describes a slower dynamics of the system.

The heat exchanges within the system can be described by,

$$
\begin{aligned}
& \dot{T}_{i}=\frac{I}{C_{i}}\left(\frac{1}{R_{i e}}\left(T_{e}-T_{i}\right)+\frac{1}{R_{i a}}\left(T_{a}-T_{i}\right)+Q_{H}+A_{w} \Phi_{s}\right) \\
& \dot{T}_{e}=\frac{I}{C_{e}}\left(\frac{1}{R_{e a}}\left(T_{a}-T_{e}\right)+\frac{1}{R_{i e}}\left(T_{i}-T_{e}\right)+A_{e} \Phi_{s}\right)
\end{aligned}
$$

where $C_{i}$ is heat capacity of interior air, $C_{e}$ is heat capacity of building envelope, $Q_{h}$ is heat supply by direct air heating, $A_{\omega}$ is exposed window area, $A_{e}$ is exposed wall area, $\Phi_{s}$ is solar radiation $W / m^{2}, R_{i a}$ is thermal resistance between interior and ambient $W / K$, $R_{i e}$ is thermal resistance between interior and building envelope $W / K, \quad R_{e a}$ is thermal resistance between building envelope and ambient, $T_{i}$ is internal temperature, $T_{e}$ is building envelope temperature, $T_{a}$ is external ambient temperature.

Equation (5) describes how the temperature of the internal building air is influenced by heat exchanges with the building envelope and direct losses to the 
external air. Heat is directly applied to the internal air by the heat pump and solar radiation through the window aperture. Equation (6) describes the building envelope temperature, which is influenced by heat exchange with the building interior, the exterior and solar radiation to the exposed wall area (as defined by shading, aspect and the angle of attack of solar radiation).

The system can be described using an electrical-thermal analogy; the heat exchange between bodies is defined by the temperature (voltage) difference and the thermal resistance (electrical resistance), the storage volume and time constants of the system are defined by the heat capacity (electrical capacitance) of the thermal bodies. Consequently, the system can be illustrated as an electrical circuit as in Figure 3.

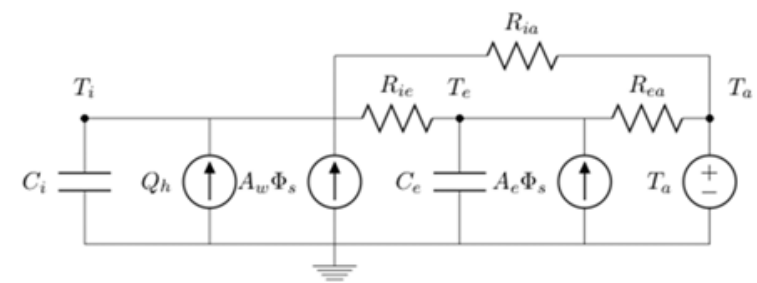

Figure 3 Electric-Thermal Analogy of Building with Direct Air Heating

A Bosch EHP AA air source heat pump (ASHP) with a heating capacity of $6 \mathrm{~kW}$ is modelled in this system. The coefficient of performance (COP) of a heat pump describes the electrical input required to achieve a given heat output. A COP value of 3 means that 1 unit of electrical input is required to achieve 3 units of heat output. The COP of this unit ranges from 2.4 to 3.3; both the COP value and the maximum heat output attainable are dependent on the temperature difference between the building interior and the external air.

\subsection{Model implementation in RSCAD}

The heat pump is implemented with two control strategies. The first one is ON/OFF control and the heat pump works at 0 or rated power with temperature range of TsetMin and TsetMax. The second one is a more advanced control and the heat pump power can be adjusted between 0 and the rated power with an inverter control. To make the controller simple a proportional controller is used. To avoid the steady state error inherent in a proportional controller the energy loss from the inside is used in addition to the actual and set point temperature. This is done by taking (5) substituting $Q_{H}=C O P \times P$ and $\dot{T}_{i}=T_{\text {set }}-T_{i}$, and then isolating $P$. $P$ is then limited to the range of the heat pump.
$P=\frac{-U_{i e}\left(T_{e}-T_{i}\right)-U_{i a}\left(T_{a}-T_{i}\right)-A_{\omega} \Phi_{s}+\left(T_{s e t}-T_{i}\right) C_{i}}{C O P}$

The inputs of the model are always the outside temperature $\left[{ }^{\circ} \mathrm{C}\right]$ and solar radiation $[\mathrm{W} / \mathrm{m} 2]$. The set point temperature is a single value for the inverter control, and a minimum and maximum value for the relay control. The heat pump model implemented in RSCAD is shown in Figure 4.

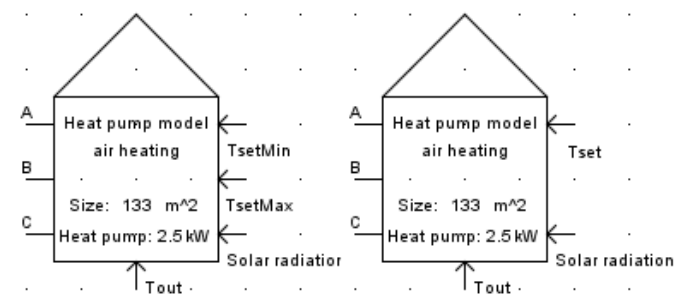

Figure 4 RSCAD Heat Pump Model with relay control (left) and inverter control (right)

The parameter configuration of the heat pump model consists of three tabs. The first tab has the required parameters and the values used for initializing the model. It is also possible to set a higher scale factor to simulate $\mathrm{X}$ identical houses instead of just one. The first tab is shown in Figure 5.

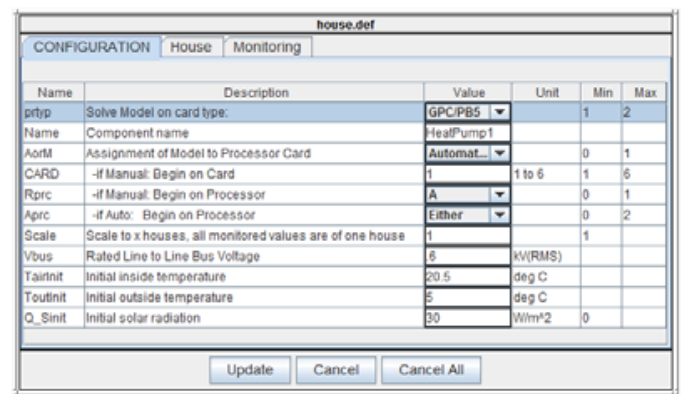

Figure 5 General Parameter Configuration of the Heat Pump Model

On the second tab, the parameters of the house and the heat pump can be adjusted. The last tab is to enable monitoring of different parameters in the model and giving the parameters name. It is possible to monitor power, COP and all the simulated temperatures and heat flows. The house parameter configuration tab is shown in Figure 6. 


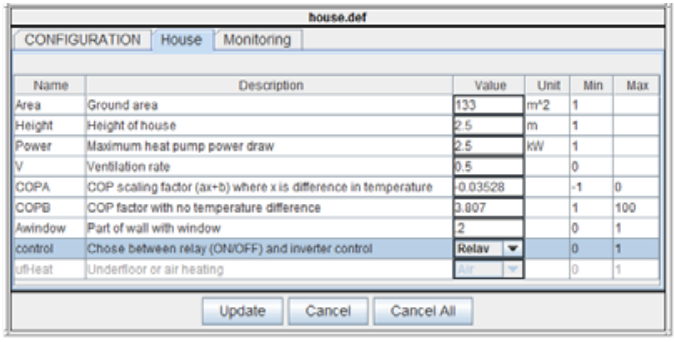

Figure 6 House Parameter Configuration of the Heat Pump Model

\section{HAREWARE-IN-THE-LOOP TEST SETUP}

A HIL test refers to a test in which parts of a pure simulation have been replaced by actual physical components. The HIL test is often used to understand the behavior of a new device, or to predict an outcome under different system conditions without knowing the detail of device design. Also, The HIL test can help build a model and validate a model of a new power device [9].

The HIL test is used to test the efficacy of the implemented DFR technology. The DFR technology is implemented as a SmartBox which can regulate demands while measuring consumption, grid frequency and other related parameters. The appearance of the SmartBox is shown in Figure 7. The SmartBox is supplied with a standard $230 \mathrm{~V}$ outlet and measures frequency, voltage and current of any load attached to the SmartBox. It can control or regulate an attached device using digital or relay signals.

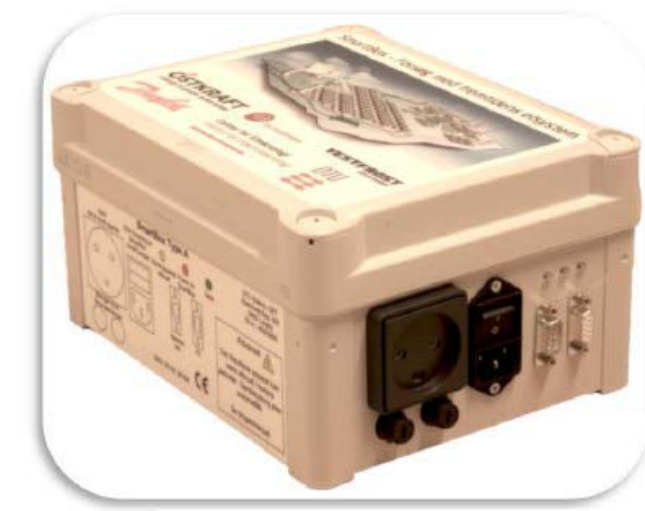

Figure 7 Appearance of the SmartBox

The HIL platform for testing the DFR is shown in Figure 8. A power system with household appliances is simulated in the RTDS. The frequency of the simulated power system is measured by the SmartBox through the GTAO card of the RTDS and the control signal to the household appliances is sent to the real time simulation through the GTDI card.

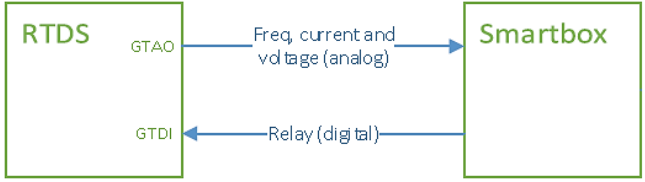

Figure 8 HIL Test Platform

\section{Test Results}

The test results are presented in this section. For the HIL test, firstly, the heat pump model in RSCAD was tested; secondly, the HIL test of the DFR was conducted with the Bornholm power system.

\subsection{Bornholm power system}

Bornholm is a Danish island located in the Baltic Sea. It is equivalent to about $1 \%$ of Denmark with regard to area, population and energy consumption. The Bornholm power system is representative of the future Danish power system with substantial wind power integration. The wind power supplies about $50 \%$ of the yearly electricity consumption. The Bornholm power system is connected to Swedish power system, and can run in island operation mode. The Bornholm power system is illustrated in Figure 9.

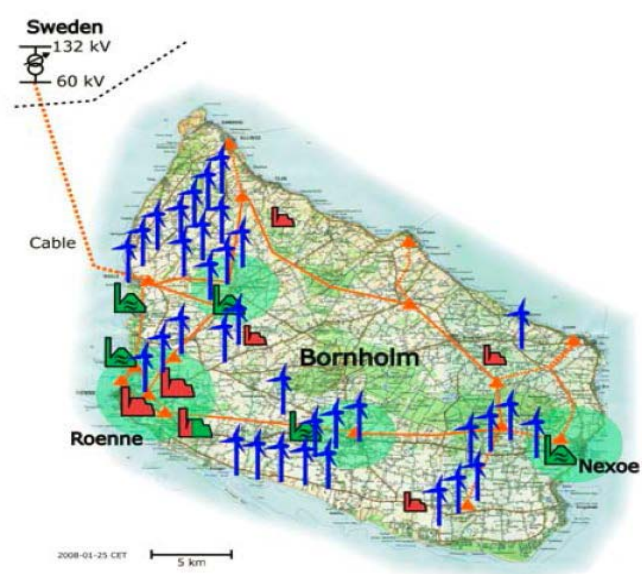

Figure 9 the Bornholm power system

\subsection{Test of the heat pump model in RSCAD}

The heat pump model implemented in RSCAD was tested in order to check the performance of the model. A small test system was built in RSCAD to test the model with both relay and inverter control modes. The heat 
pump model is connected an external grid with a breaker. The test system is shown in Figure 10.

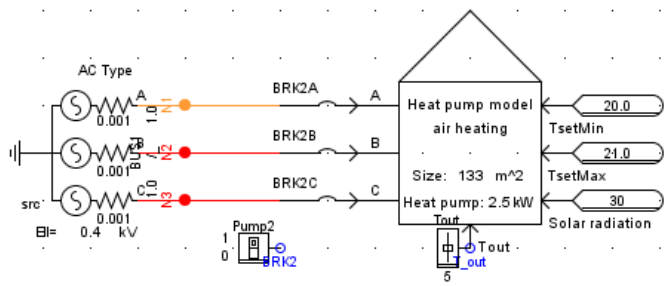

Figure 10 Heat Pump Model Test System

Two tests were conducted for the relay control and the inverter control. The test results with the relay control are shown in Figure 11. It is shown that the heat pump works as expected, i.e. the heat pump turns off if the maximum temperature is hit, and the heat pump turns on if the minimum temperature is reached.
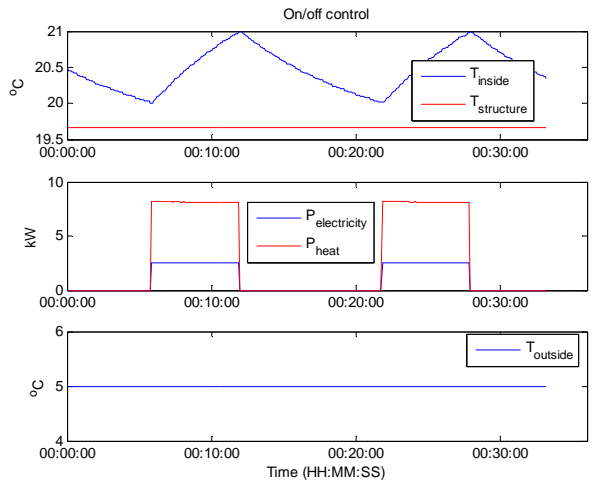

Figure 11 Test Results of Heat Pump Model with Relay Control

The test results of the heat pump model with inverter control are shown in Figure 12. At around 13 minutes, the breaker between the source and the model was switched off for a short period. The inside temperature drops in this period and as soon as the power is restored, the heat pump restarts at full power until the temperature is restored to the set point. In the end, the outside temperature is changed and the controller immediately changes the heat pump output such that the temperature is kept constant.

The tests results of the heat pump model with both relay control and inverter control show that the heat pump model works as expected.
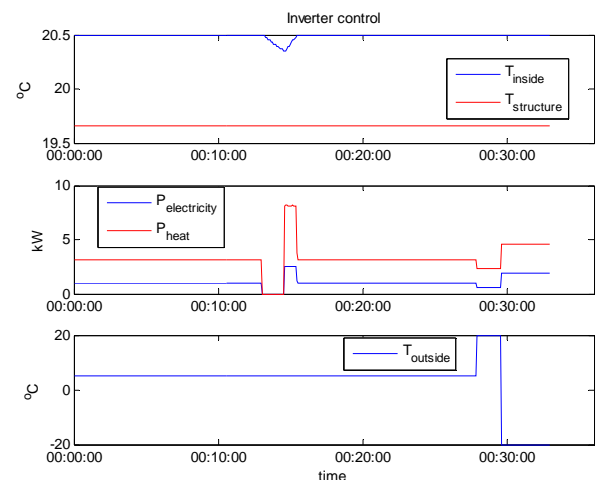

Figure 12 Test Results of Heat Pump Model with Inverter Control

\subsection{HIL test of the DFR}

In order to verify the effectiveness of the DFR, a number of scenarios are defined. In each of the scenario, a specific change of the system demand is set as a contingency to the system. Two system demand changes are selected which are $5 \%$ demand increase and decrease. The DFR penetration levels are set as $0 \%, 2.5 \%, 5 \%$ and $7.5 \%$. The test scenarios are listed in Table 1 . The test results are shown in Figure 13 and Figure 14.

Table 1: Test Scenarios

\begin{tabular}{|c|c|c|c|c|c|}
\hline $\begin{array}{c}\text { Contingency } \\
\text { Type }\end{array}$ & $\begin{array}{c}\text { Ratio of } \\
\text { Demand } \\
\text { Change }\end{array}$ & \multicolumn{4}{|c|}{ DFR penetration level } \\
\hline $\begin{array}{c}\text { Demand } \\
\text { increase }\end{array}$ & $5 \%$ & $0 \%$ & $2.5 \%$ & $5 \%$ & $7.5 \%$ \\
\hline $\begin{array}{c}\text { Demand } \\
\text { decrease }\end{array}$ & $5 \%$ & $0 \%$ & $2.5 \%$ & $5 \%$ & $7.5 \%$ \\
\hline
\end{tabular}

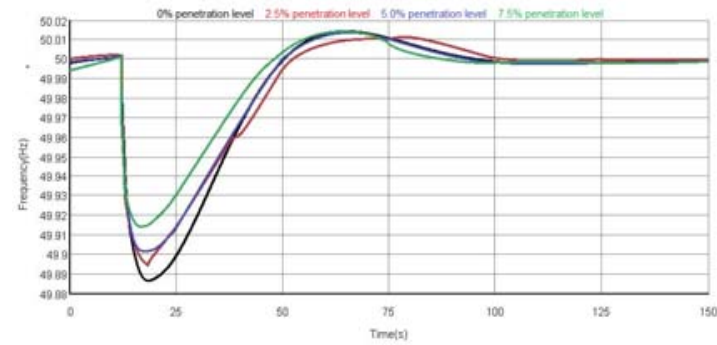

Figure 13 System Frequency with 5\% Demand Increase 


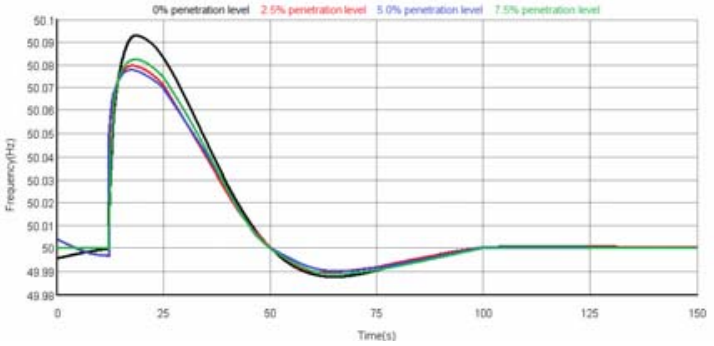

Figure 14 System Frequency with 5\% Demand Decrease

The test results show that the DFR can help arrest the frequency deviation. The higher the DFR penetration, the lower the frequency deviation. The HIL test verifies the efficacy of the DFR technology.

\section{CONCLUSION}

The DFR technology has been developed to utilize the demand side resources to provide fast reserves needed in the future renewable based power system. The DFR technology has been tested by offline simulations in the previous work. The real time HIL tests were conducted to verify the effectiveness of the DFR technology. The HIL test results show that the DFR technology can successfully arrest the system frequency and illustrate the efficacy of the SmartBox.

The future work will be done with the Nordic power system to illustrate the efficacy of the DFR.

\section{ACKNOWLEDGMENT}

The authors are grateful to the financial support from Energinet.DK.

\section{REFERENCES}

[1] The Danish Government (2011, Feb.). Energy strategy 2050. Copenhagen, Denmark. [Online]. Available:

http://www.ens.dk/sites/ens.dk/files/dokumenter/pu blikationer/downloads/energy_strategy_2050.pdf (accessed on 04-Aug-2014).

[2] M. Bailey, "Provision of frequency responsive power reserve from disconnectable load,” Proc. IEE Colloq. Economic Provision of a Frequency Responsive Power Reserve Service (98/190), pp. 5/1-5/5, Feb. 1998.

[3] A. Turner, T. N. Chan, and A. N. Gibbs, “A fast reacting power system load shedding management system,” in Proc. 9th Conf. Electric Supply Industry (CEPSI), Hong Kong, 1992.

[4] B. J. Kirby, Spinning Reserve Provided From Responsive Loads. Oak Ridge, TN: Oak. Ridge Nat. Lab., 2003.

[5] Kintner-Meyer, M., Guttromson, R., Oedingen D., Lang, S.: Final Report for California Energy Commission: Smart Load and Grid-Friendly Appliances, Architecture Energy Corporation and Battelle Memorial Institute, 2003.

[6] PNNL: Grid Friendly ${ }^{\mathrm{TM}}$ Controller Helps Balance Energy Supply and Demand. [Online]. Available: http://www.gridwise.pnl.gov/docs/pnnlsa36565.pdf.

[7] Xu, Z., Østergaard, J., Togeby, M.: Demand as Frequency Controlled Reserve-Final Report of the PSO Project, Technical University of Denmark and Ea Energy Analyses, 2008.

[8] Xu, Z., Østergaard, J., Togeby, M.: ‘', IEEE Transactions on Power Systems, vol. 26, no. 3, 2011, pp. 1062-1071.

[9] Wu, J., Cheng, Y., Srivastava, A. K., Schulz, N. N., Ginn III, H. L.: 'hardware in the loop test for power system modeling and simulation', in Proc. 2006 Power System Conference and Exposition. 